\title{
Research Article \\ Bibliometric Study of the Comorbidity of Pain and Depression Research
}

\author{
Xue-Qiang Wang $\mathbb{D}^{1,2}$ Meng-Si Peng, ${ }^{1}$ Lin-Man Weng, ${ }^{1}$ Yi-Li Zheng, ${ }^{1}$ Zhi-Jie Zhang $\mathbb{D}^{3}$ \\ and Pei-Jie Chen (iD) 1,2 \\ ${ }^{1}$ Department of Sport Rehabilitation, Shanghai University of Sport, 399 Changhai RD, Shanghai 200438, China \\ ${ }^{2}$ Department of Rehabilitation Medicine, Shanghai Shangti Orthopaedic Hospital, 188 Hengren RD, Shanghai 200438, China \\ ${ }^{3}$ Luoyang Orthopedic Hospital of Henan Province, 82 Qimingnan RD, Luoyang 471000, China
}

Correspondence should be addressed to Zhi-Jie Zhang; sportspt@163.com and Pei-Jie Chen; chenpeijie@sus.edu.cn

Received 28 June 2019; Accepted 27 August 2019; Published 23 October 2019

Academic Editor: Nicoletta Berardi

Copyright (c) 2019 Xue-Qiang Wang et al. This is an open access article distributed under the Creative Commons Attribution License, which permits unrestricted use, distribution, and reproduction in any medium, provided the original work is properly cited.

\begin{abstract}
Background. Comorbid pain and depression occur with high prevalence in clinical observations, and published academic journals about them have been increasing in number over time. However, few studies used the bibliometric method to analyze the general aspects of scientific researches on the comorbidity of pain and depression. The aim of this study is to systematically provide global scientific research in the comorbidity of pain and depression from 1980 to 2018. Methods. The published papers were searched between 1980 and 2018 in Web of Science. Publications related to comorbid pain and depression research were included. The language was restricted to English, and no species limitations were specified. Results. A total of 2,519 papers met the inclusion criteria in our study. The results revealed that the publications had a significant growth over time in the comorbidity of pain and depression research $(P<0.001)$ by linear regression analyses. The United States had the largest number of publications and citations and the highest value of $H$-index. According to subject categories of Web of Science, research areas of the 2,519 papers mainly focused on clinical neurology $(28.78 \%)$, neurosciences $(22.9 \%)$, and psychiatry $(22.23 \%)$. In accordance with types of pain, headache $(19.09 \%)$ was the most popular topic in the included papers on comorbid pain and depression research. Conclusions. The findings provide useful information for pain and depression researchers to detect new areas related to collaborators, cooperative institutions, popular topics, and research frontiers.
\end{abstract}

\section{Introduction}

Pain is the most pervasive physical symptom in primary care, which affects physical and emotive functions, deteriorates the quality of life, and reduces the ability to work [1-4]. The prevalence of chronic pain has been estimated to be as high as $40 \%$ in the United States [5]. The most common types of pain syndromes [6-8] include headache, low back pain, fibromyalgia, neuropathic pain, arthritis, cancer, and postsurgical pain. The total cost of pain has been calculated to be as high as 3\% of the gross domestic product of European countries, which is larger than the cost of cancer or heart disease [9]. Depression is the most common psychological symptom and is a major public health concern in primary care $[10,11]$. The prevalence of depressive symptoms or depression among medical students from 43 countries has been reported to be $27.2 \%$ [12], and the lifetime prevalence of depression in 30 countries has been calculated to be $10.8 \%$ [13]. In Japan, the total cost of depression among adults was estimated to be $¥ 2.0$ trillion in 2005 [14].

Comorbid pain and depression occur with high prevalence in clinical observations, as high as 60\% [4]. A number of studies have reported that antidepressant drugs have been used to treat pain since the 1960s [4, 15]. Pain intensity is aggravated by increasing levels of depression [16]. Although the neurobiological mechanisms of the interaction between pain and depression are unclear, human neuroimaging studies indicate that depression can influence changes in multiple brain regions including those related to pain processing and perception $[17,18]$. 


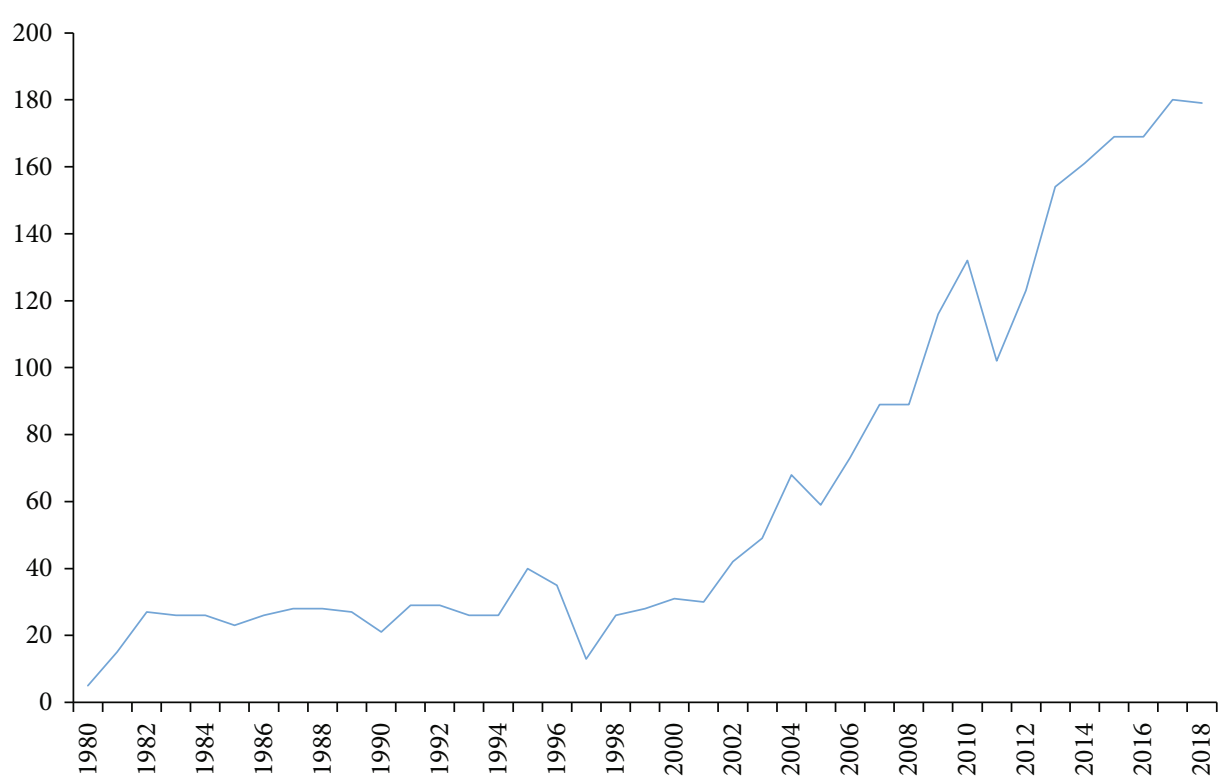

(a)

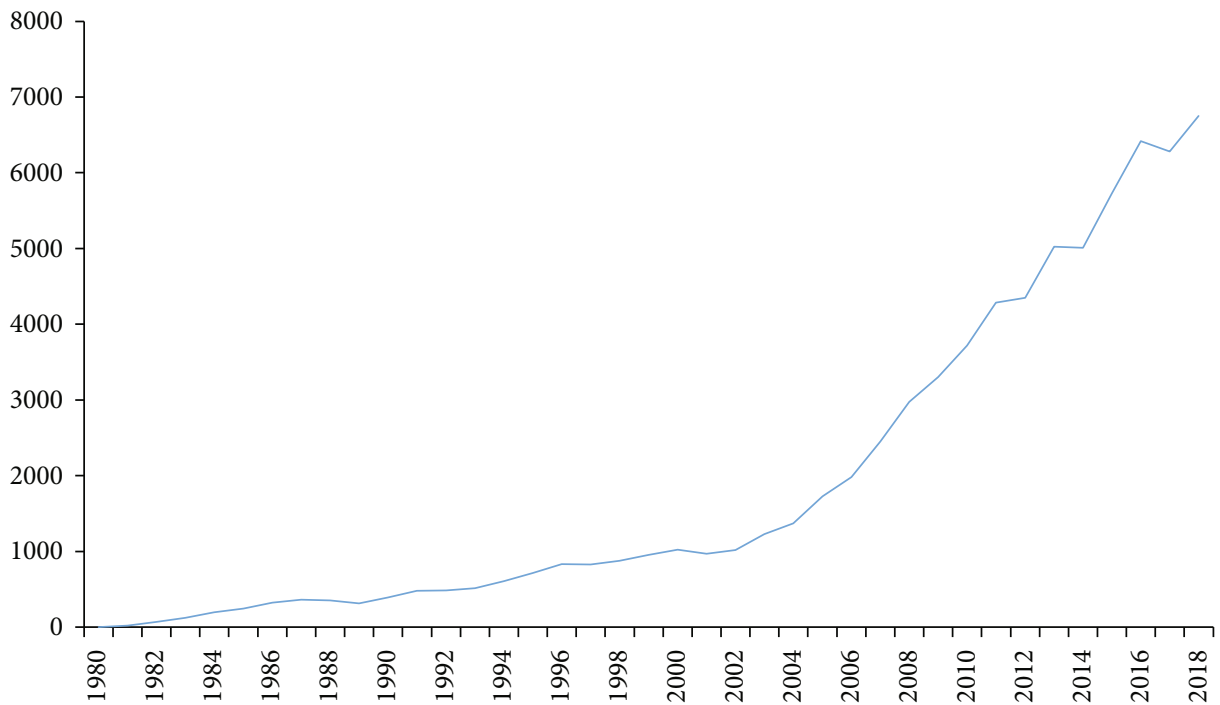

(b)

Figure 1: Number of publications and citations. (a) The number of annual publications on pain and depression research from 1980 to 2018 ; (b) the number of annual citations on pain and depression research from 1980 to 2018.

While research on comorbid pain and depression is widely available worldwide, relatively few studies use bibliometric methods to analyze the general aspects of this research topic. Bibliometric studies are extensively used to determine trends of scientific research and involve quantitative analysis of published studies $[19,20]$. This type of study could offer readers quantitative information on distribution by country, institution, author, and journal in a specific field. Over the last 10 years, bibliometric studies have been used to analyze scientific research in different areas, such as long noncoding RNA [21], paediatric pain [22], cancer rehabilitation [23], childhood immunization [24], eye disease [25], and drug delivery [26], worldwide.

To address the shortage of quantitative analysis of comorbid pain and depression research, the aim of this study is to systematically provide global scientific research in this field from 1980 to 2018. We used CiteSpace V (Drexel University, Philadelphia, United States) to perform a bibliometric study in Web of Science Core Collection, which is a tool frequently used to assess the trends in the global scientific research [27]. In this study, global scientific research on comorbid pain and depression includes the number of published papers, types of pain, distribution and collaborations between authors/institutions/countries, a citation burst analysis of keywords, cocitation analysis of authors and references.

\section{Methods}

2.1. Sources of the Data. The published papers were searched in the recent forty years (from 1980 to 2018). We downloaded and extracted the publications from Science Citation 


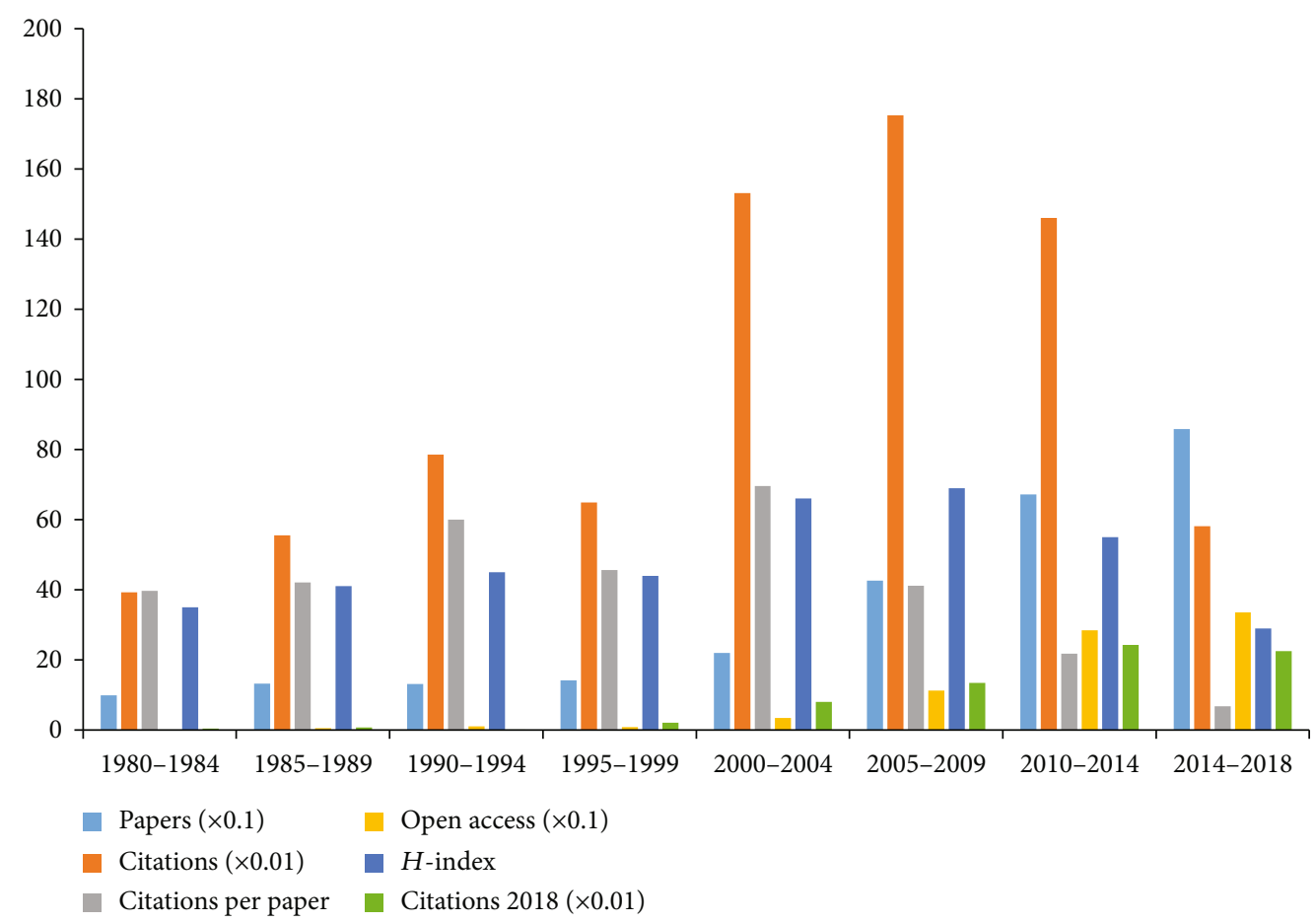

Figure 2: Number of papers, citations, citations per paper, open access paper, $H$-index, and citations in 2018 for each 5 -year time period.

Index Expanded (SCI-Expanded) of Web of Science. The following terms were searched: Title $=($ pain $*$ or headache $*$ or migraine* or head-ache* or "head ache*" or cephalalgi* or "abdominal ache*" or fibromyalg* or "tummy ache*" or "stomach ache*" or "belly ache*" or ear-ache* or earache* or tooth-ache* or toothache* or odontalgi* or neuralgi* or cervicodyn $*$ or analg* or nocicept* or hyperalg* or hypoalg* or radiculalg* or colic or arthralg* or causalg* or maldyn $*$ or eudyn $*$ or ophthalmodyn $*$ or cephalalg* or dysmenorrh $*$ or sciatic* or otalg* or brachialg*) and Title $=($ depression or depressions or depressed or despondent or gloomy or depressive).

2.2. Inclusion Criteria. We included articles, reviews, letters, and editorial materials published in different academic journals. Meeting abstracts, conference presentations, book reviews, news items, and corrections were excluded. Publications related to comorbid pain and depression research were included. The language was restricted to English, and no species limitations were specified.

2.3. Data Extraction. The two authors (Lin-Man Weng and Xue-Qiang Wang) extracted the publications and used EndNote (EndNote X7, Bld 7072, Thomson Research Soft, Stamford) and Microsoft Excel 2016 to perform the downloaded published studies. We extracted and recorded pertinent information, such as publication count, journal, institution, country, and citation frequency, as bibliometric indicators. The $H$-index is recognized as a measurement of the papers' citation frequency for academic journals or researchers. For example, the $H$-index is that an academic journal or researcher has $H$ published papers which have at least $H$ cita- tion times per paper (If the $H$-index of one researcher is 10 , that means that he had published at least 10 papers and each of these 10 papers had been cited at least 10 times.) [28]. Furthermore, these included studies that were classified into the following categories: (1) single- or multiple-authored publications (authors $\geq 2$ ); (2) Web of Science subject category. We would select and assess the top 20 subject categories of Web of Science categories according to the included studies. Every paper or journal is assigned to at least one Web of Science category in Web of Science core collection. Thus, the sum of publications could be more than 2,519. Research areas were classified into five broad categories in Web of Science categories, and the five broad categories included 225 subject categories [29], such as anesthesiology, neurosciences, and psychiatry; (3) types of pain. We would choose and analyze the top ten types of pain (such as headache and low back pain) according to the included studies. Because some papers exceeded one type of pain, the sum of publications could be more than 2,519. For example, the paper by Gesztelyi and Bereczki included headaches and low back pain [30].

2.4. Statistical Methods. CiteSpace V and Microsoft Excel 2016 were used to (1) analyze the distribution by journals, years, countries, institutions, and authors, (2) assess the collaborations between countries, institutions, and authors, (3) perform analysis of citations and $\mathrm{H}$-index, and (4) conduct analysis of reference and keywords. In addition, we calculated a percentage score each year for some categories (all the articles were divided into different categories, the number of publications per year of one category divided by the total number of publications of this category), such as singleauthored publications and multiple-authored publications, 


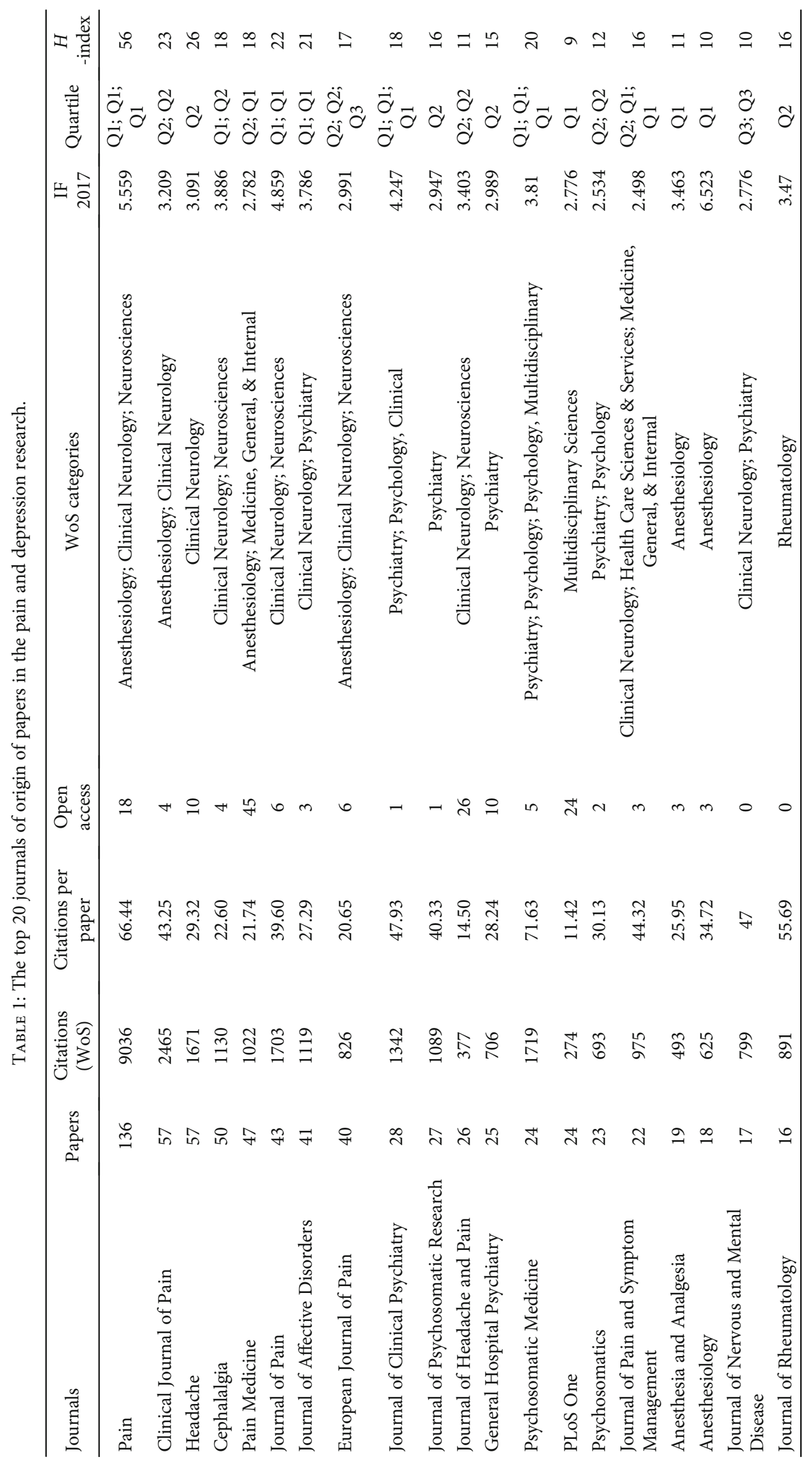




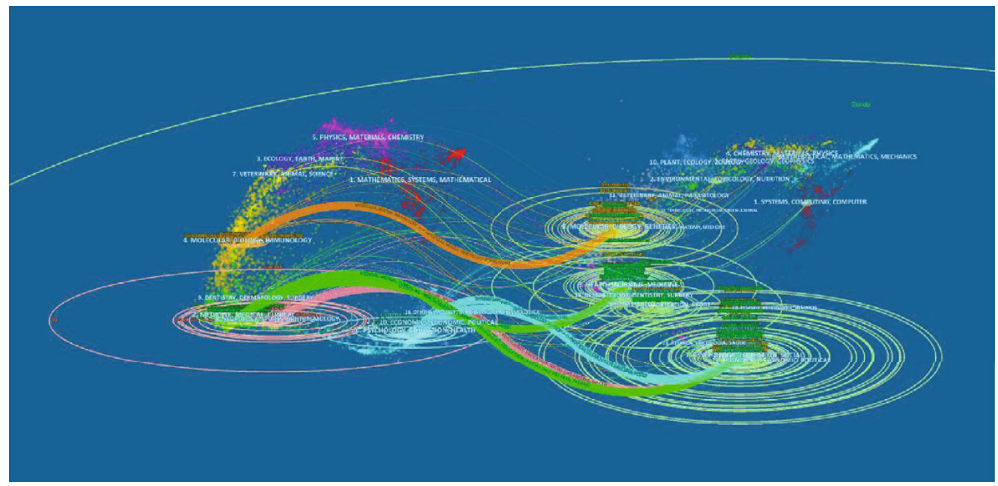

FIgURE 3: The dual-map overlay of journals related to pain and depression research.

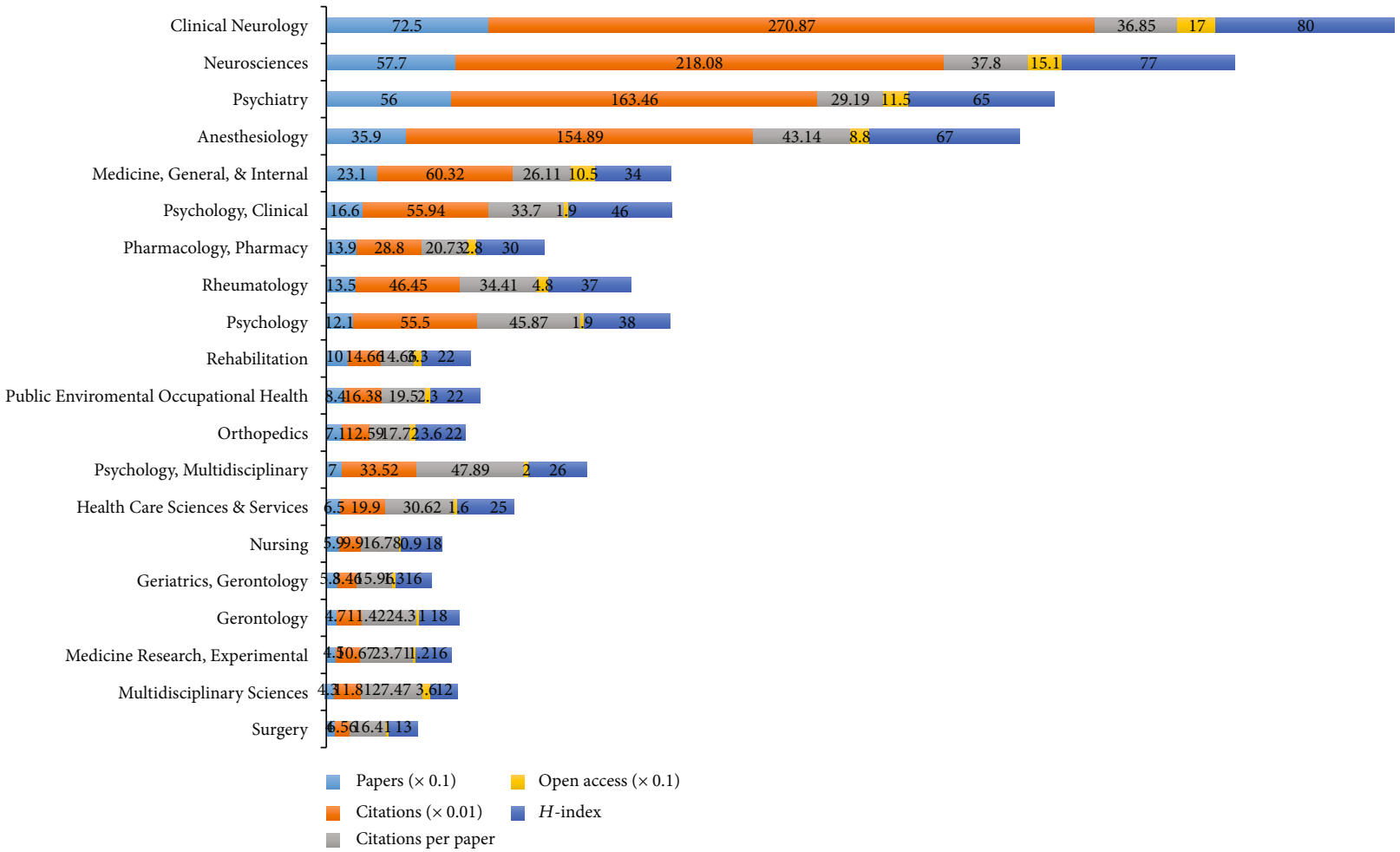

Figure 4: The number of papers, citations, citations per paper, open access papers, and H-index of the top 20 subject categories of Web of Science.

subject categories of Web of Science, and types of pain. To assess whether the percentage statistically decreased or increased over time, the linear regression analyses were conducted with every respective category as the dependent variable and the year as the independent variable. The statistical analyses were performed with IBM SPSS Statistics 22.0 software (SPSS Inc., Chicago, USA). A $P$ value less than 0.05 was considered as statistical significance.

\section{Results}

3.1. Publication Outputs and Growth Trends. A total of 2,519 papers met the inclusion criteria; 1,264 papers (meeting abstracts, proceedings papers, notes, corrections, book reviews, and news items) and 151 non-English papers were excluded (Supplementary Figure 1). The overall trend of publications increased from five publications in 1980 to 179 publications in 2018 (Figure 1(a)). The results of linear regression analyses showed that the percentages had a significant increase over time in the recent forty years $(t=11.37, \quad P<0.001)$. All papers related to comorbid pain and depression research were cited 74,746 times (29.67 times per year, $H$-index 121), and the percentages had a significant increase over time $(t=12.47, P<0.001)$ (Figure 1(b)). Among the eight 5 years (1980-1984, 19851989, 1990-1994, 1995-1999, 2000-2004, 2005-2009, 20102014, and 2014-2018), 2005-2009 had the largest number of citations $(17,528)$ and the highest value of $H$-index (66), 2000-2004 had the largest number of citations per paper (69.58), 2010-2014 had the largest number of 


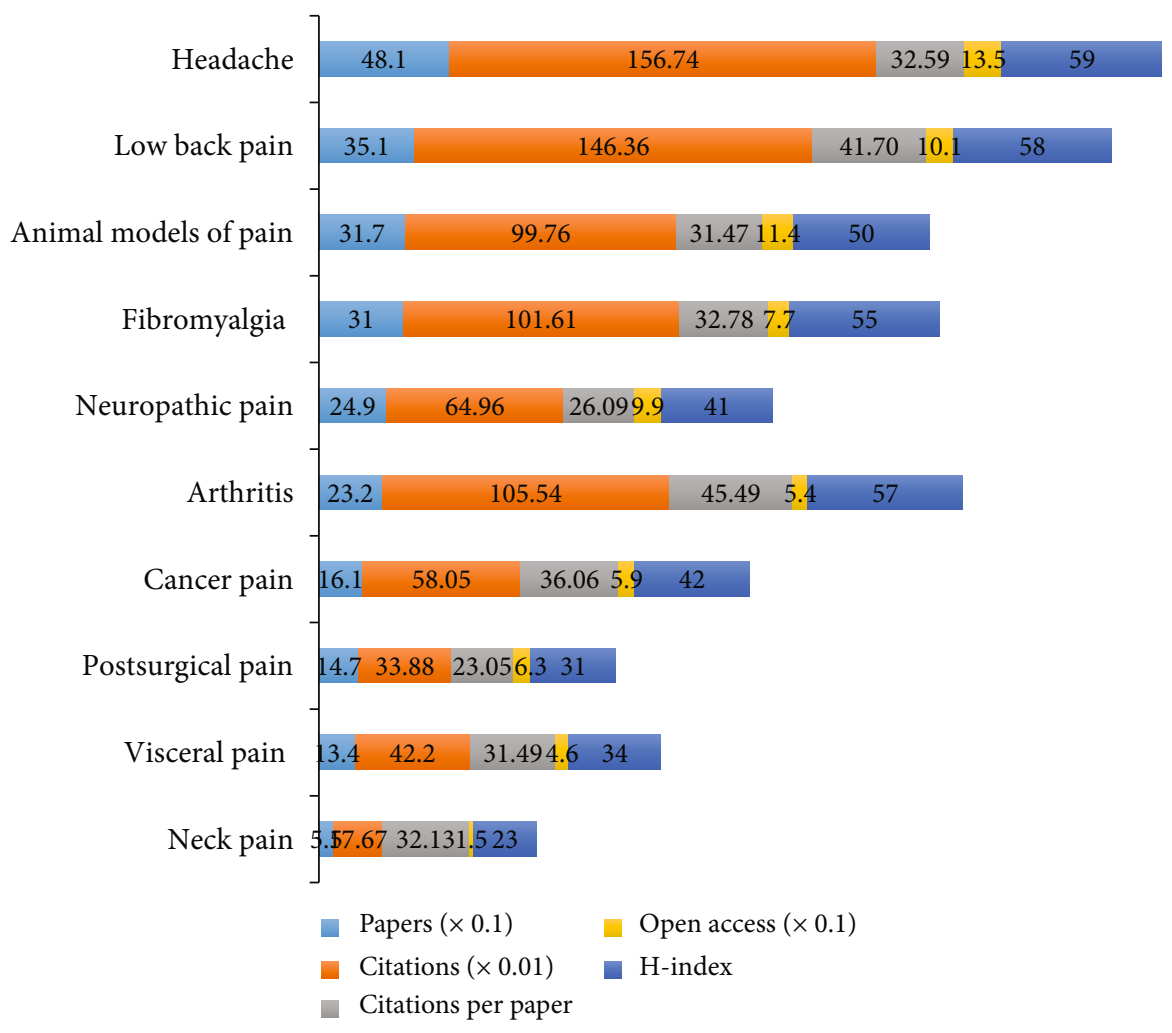

FIGURE 5: The number of papers, citations, citations per paper, open access papers and H-index of the top 10 types of pain.

citations (2429) in 2018, and 2014-2018 had the largest number of publications (858) and open access papers (335) (Figure 2).

3.2. Distribution by Journals. The 2,519 papers on comorbid pain and depression research were published in 251 academic journals (Supplementary Table 1). Among the top 20 journals by the number of publications (Table 1), Pain, in which impact factor (IF) 2017 was 5.559, contributed to the most publications on comorbid pain and depression research (136 publications, 5.39\%), followed by Clinical Journal of Pain (IF 2017, 3.209; 57 publications; 2.26\%), Headache (IF 2017, 3.091; 57 publications; 2.26\%), and Cephalalgia (IF 2017, 3.886; 50 publications; 1.98\%). The top 20 journals contributed to $29.37 \%$ of the total number of publications. The highest value of $H$-index was with Pain (97), the largest number of citations per paper was with Psychosomatic Medicine (IF 2017, 3.81), and the highest value of IF 2017 was with Anesthesiology (IF 2017, 6.523). In journal IF quartile of Web of Science, $55 \%$ of journals were Q1 (Q1 stands for the top 25\% of the IF distribution) and $40 \%$ of journals were Q2 (Q2 stands for between top $50 \%$ and top $25 \%$ of the IF distribution) among the 20 journals.

A dual-map overlay of journals is presented in Figure 3. In the dual-map, the map of the citing journals is on the left and the map of the cited journals is on the right. The disciplines included in the journals are shown as labels in the dual map. The lines are considered citation connections, beginning from the citing journals to the cited journals. The dual-map overlay shows that the majority of papers were published in neurology, sports, and ophthalmology journals and these journals mostly cited journals from psychology, education, and social areas.

3.3. Subject Categories of Web of Science. Research areas of the 2,519 papers on comorbid pain and depression research were assigned to 55 subject categories of Web of Science. In top 20 subject categories (Figure 4), according to the number of publications, Clinical Neurology had the largest number of publications (725), citations $(27,087)$, and open access papers (170) and the highest value of H-index (80). The Psychology Multidisciplinary subject category had the largest number of citations per paper (47.89). Moreover, the results of linear regression analyses showed that the percentages of publication count per year had a statistical increase over time $(P<0.01)$ in the top 20 subject categories (Clinical Neurology, Neurosciences, Psychiatry, Anesthesiology, Medicine General Internal, Psychology Clinical, Pharmacology Pharmacy, Rheumatology, Psychology, Rehabilitation, Public Environmental Occupational Health, Orthopedics, Psychology Multidisciplinary, Health Care Sciences Services, Nursing, Geriatrics Gerontology, Gerontology, Medicine Research Experimental, Multidisciplinary Sciences, and Surgery).

3.4. Types of Pain. As shown in Figure 5, according to the number of publications, headache (19.09\%) was the most popular topic in the included papers on comorbid pain and depression research, followed by low back pain, animal models of pain, and fibromyalgia. Among the top 10 types 


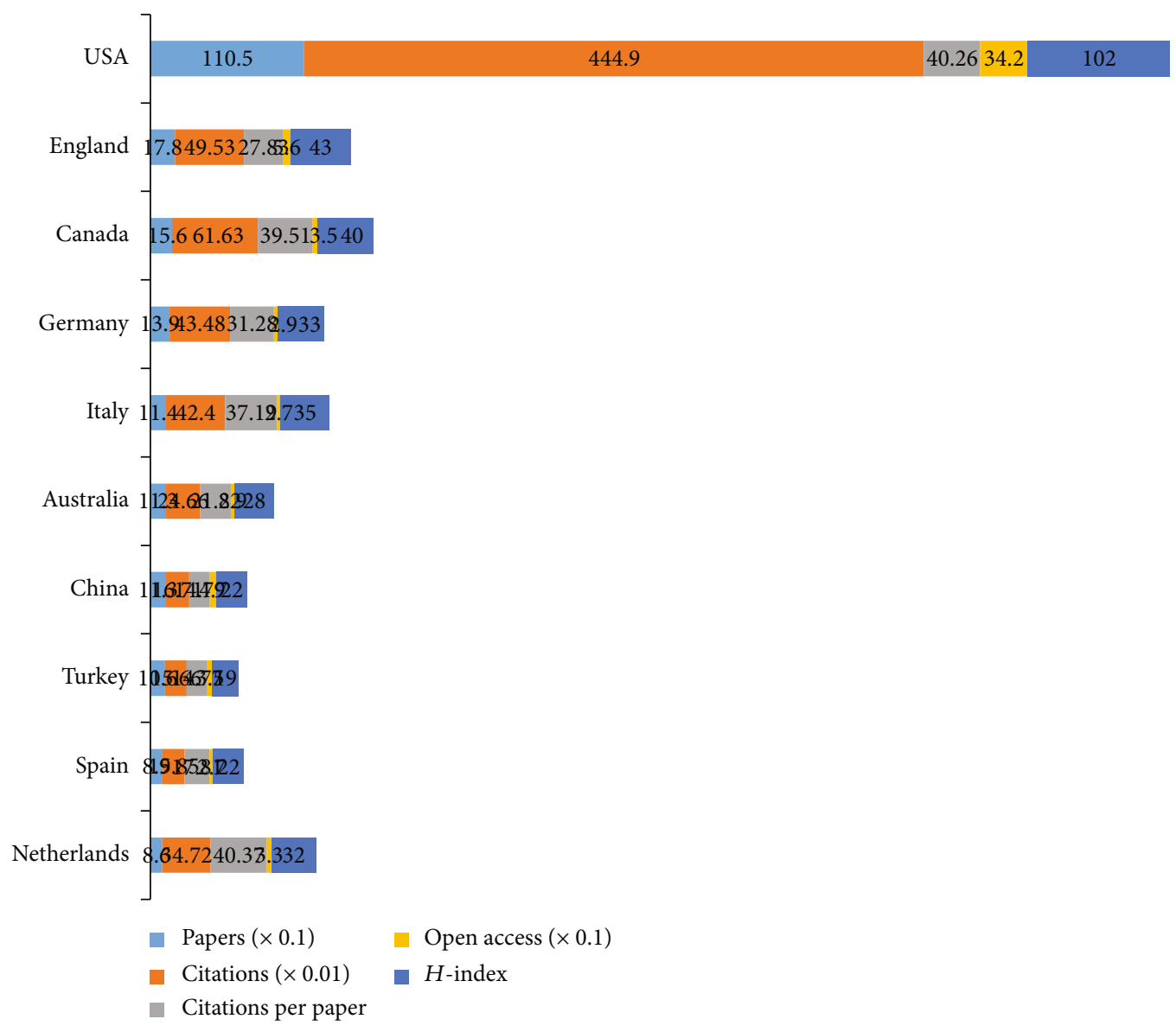

Figure 6: The number of papers, citations, citations per paper, open access papers, and $H$-index of the top 10 countries.

of pain, headache had the largest number of publications (481), citations $(15,674)$, and open access papers (135) and the highest value of $H$-index (59). Arthritis had the largest number of citations per paper (45.49). In addition, the results showed that the percentages of publication count per year had a significant increase over time $(P<0.01)$ in headache, low back pain, animal models of pain, fibromyalgia, neuropathic pain, arthritis, cancer pain, postsurgical pain, visceral pain, and neck pain.

3.5. Distribution by Countries and Institutions. The 2,519 papers on comorbid pain and depression research were contributed by 75 countries/territories (Supplementary Table 2). Figure 6 shows the top 10 countries/territories by quantity of papers, showed as sums of paper fractions. The United States had the largest number of publications $(1,105)$, citations $(44,490)$, and open access papers (342) and the highest value of $H$-index (102). The Netherlands had the largest number of citations per paper (40.37). In relation to the top 10 countries that contributed to comorbid pain and depression research, USA led the first research echelon, followed by the England (178), Canada (156), and Germany (139). There were extensive collaborations between countries/territories (Figure $7(\mathrm{a})$ ). In accordance with the number of published papers, the overview of all countries was presented in world map (Figure 8).
A total of 1,884 institutions contributed to the publications on comorbid pain and depression research (Supplementary Table 3). The top 10 institutions (Supplementary Figure 2) contributed to $30.77 \%$ of the total number of publications. The University of California System had the largest number of publications (108), University of Washington had the largest number of citations $(5,680)$, Eli Lilly had the largest number of citations per paper (108), and Harvard University had the largest number of open access papers (45) and the highest value of $\mathrm{H}$-index (37). Figure 7(b) showed the network map of institutions engaged in pain and depression research.

3.6. Distribution by Authors. A total of 8,771 authors contributed to the total number of publications. The network map in Figure 9 outlines the cooperation between authors. Amongst the authors who had the most publications (Table 2), Kroenke $\mathrm{K}$ ranked the first with 35 publications, followed by Bair MJ with 21 publications, Negus SS with 19 publications, and Wang SJ with 19 publications. Amongst the top 10 cocited authors (Table 2), Bair MJ with 447 citations, followed by Beck AT with 403 citations, Kroenke K with 337 citations, and Turk DC with 236 citations were the most popular. Figure 10 indicates that the percentages of multipleauthor papers $(\geq 2)$ increased from $65.66 \%$ in $1980-1984$ to $96.27 \%$ in $2014-2018$. The linear regression results revealed that the percentage of papers with multiple authors 


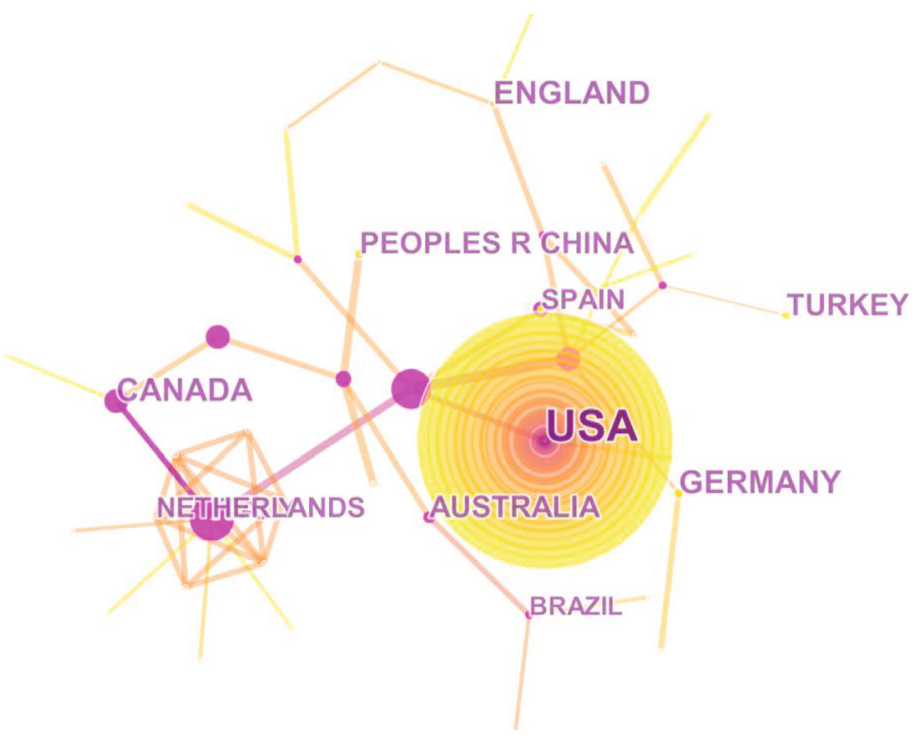

(a)

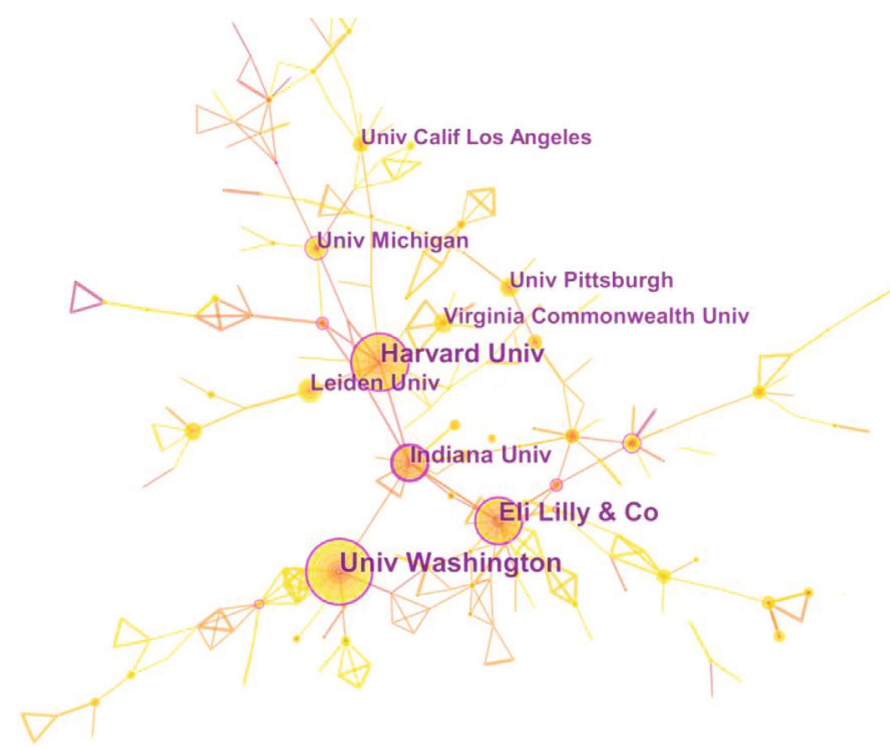

(b)

Figure 7: The analysis of countries and institutions. (a) Network map of countries/territories engaged in pain and depression research; (b) network map of institutions engaged in pain and depression research.

significantly increased and that with a single author significantly decreased $(t=11.76, P<0.001)$.

3.7. Analysis of References. Analysis of references was regarded as an important indicator in bibliometric study. The scientific relevance of the published papers was presented in the cocitation map of references (Figure 11). The modularity $Q$ score was 0.8897 (higher than 0.5 ), which indicated that the network was reasonably distributed to loosely coupled clusters. All clusters were traced by index terms extracted from the references. The "rehabilitation outcome" was labeled as the largest cluster \#0, followed by "home care" as the second largest cluster \#1, "pain comorbidity" as the third largest cluster \#2, and "depressive disease." As shown in Figure 11, the top 23 clusters were showed in a timeline view.
3.8. Analysis of Keywords. The keywords of the 2,519 published papers were extracted by CiteSpace V. Figure 12 reveals the top 47 keywords with the strongest citation bursts. Keywords with the strongest citation bursts beginning in 1991 were as follows: "disease," "illness," "chronic pain," and "inventory." The top 47 keywords by the end of 2018 included "older adult" (2014-2018), "validity" (2015-2018), "impact" (2016-2018), and "association" (2016-2018).

3.9. Characteristics of Top 10 Papers Cited Most Frequently. Table 3 showed the top ten papers on comorbid pain and depression research with the most citation frequency. The top 10 papers contributed to $7.81 \%$ (5,831 citations) of the total number of citations. The article by Bair et al. [31] published in 2003 was the most cited (1,442 citations) paper, and the article is entitled "Depression and pain 


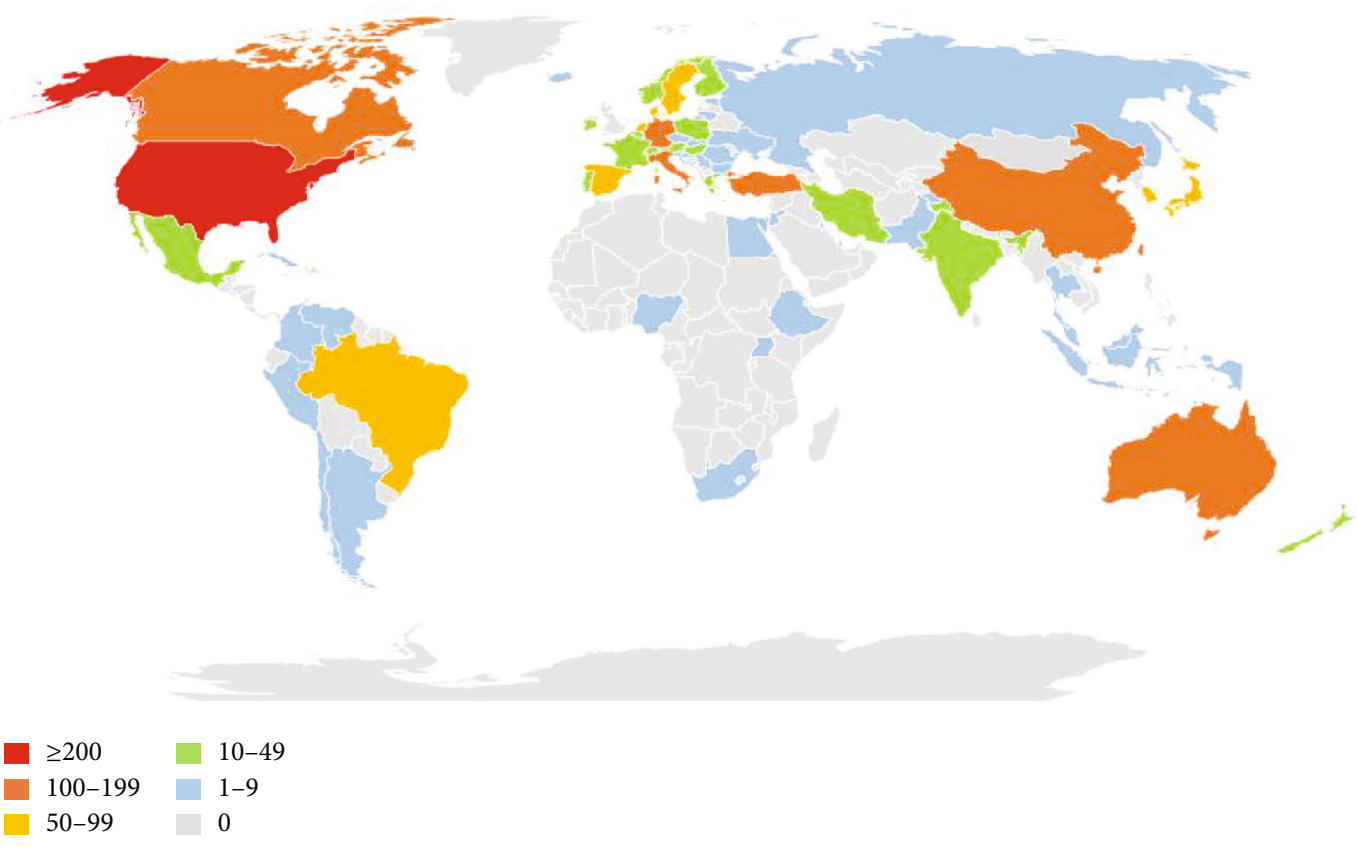

Figure 8: World map of total country output based on pain and depression research.

comorbidity-a literature review." published in Archives of Internal Medicine. Among the top 10 papers, five [3135] were published in journals with impact factor $\geq 10$ (Archives of Internal Medicine, Brain, Psychological Bulletin and Neuron), two [36,37] in journals with $5 \leq$ impact factor $<10$ (Neurology, Arthritis \& Rheumatology), two [38, 39 ] in journals with $3 \leq$ impact factor $<5$ (Clinical Journal of Pain, Journal of Pain), and one [40] journal with $1 \leq$ impact factor $<3$ (The Journal of Nervous and Mental Disease).

\section{Discussion}

4.1. Global Trends of the Comorbidity of Pain and Depression Research. The results of our bibliometric study provide a systematic overview on the comorbidity of pain and depression research in the recent forty years. The global trends of published papers showed a statistical continued growth over time in the comorbidity of pain and depression research. Although the percentage of publication increased steadily year by year, a noticeable growth was found between 2001 and 2004 in the year-over-year percentage of publication. Among the eight 5 years, 2014-2018 had the largest number of publications (858) and 2005-2009 had the largest number of citations $(17,528)$ and the highest value of $H$-index $(66)$.

In accordance with the number of publications on comorbid pain and depression research, the top 20 journals contributed to $29.37 \%$ (740 publications) of the total number of publications. Pain contributed to the most publications on comorbid pain and depression research (5.39\%) followed by Clinical Journal of Pain (2.26\%), Headache (2.26\%), and Cephalalgia (1.98\%). According to the impact factors of the journals in the Journal Citation Reports (2017 edition), the impact factors were less than 10 among the top 20 journals. In the top 20 journals, the journals with $2 \leq$ impact factor $<3$ contribute to $40 \%$ of the top 20 jour- nals, the journals with $3 \leq$ impact factor $<5$ contribute to $50 \%$, and the journals with $5 \leq$ impact factor $<10$ contribute to $10 \%$. However, according to journal IF quartile of Web of Science, 55\% of the top 20 journals were Q1 and 40\% of the top 20 journals were Q2.

In accordance with the number of publications, USA led the first research echelon $(1,105)$, followed by England (178), Canada (156), and Germany (139). And the top 10 countries were from five European countries, three AsiaPacific countries, and two American countries. As demonstrated in Figure 7, it had an extensive collaboration between countries. A total of 1,884 institutions contributed to the publications on comorbid pain and depression research. According to the number of publications, nine institutions were from USA and one from England. Compared with the cooperation of countries, the institutions were not significant.

4.2. Research Focuses on the Comorbidity of Pain and Depression Research. According to subject categories of Web of Science, the most popular research areas were Clinical Neurology (725), followed by Neurosciences (577), Psychiatry (560), and Anesthesiology (359). The top 10 subject categories were Clinical Neurology, Neurosciences, Psychiatry, Anesthesiology, Medicine General Internal, Psychology Clinical, Pharmacology Pharmacy, Rheumatology, Psychology, and Rehabilitation. On the basis of types of pain, research topics of the 2,519 papers mainly focused on headache and low back pain for the comorbid pain and depression research. Among the top 10 types of pain (headache, low back pain, animal models of pain, fibromyalgia, neuropathic pain, arthritis, cancer pain, postsurgical pain, visceral pain, and neck pain), headache had the largest number of publications (481), citations $(15,674)$, and open access papers (135) and the highest value of $\mathrm{H}$-index (59). According to the 


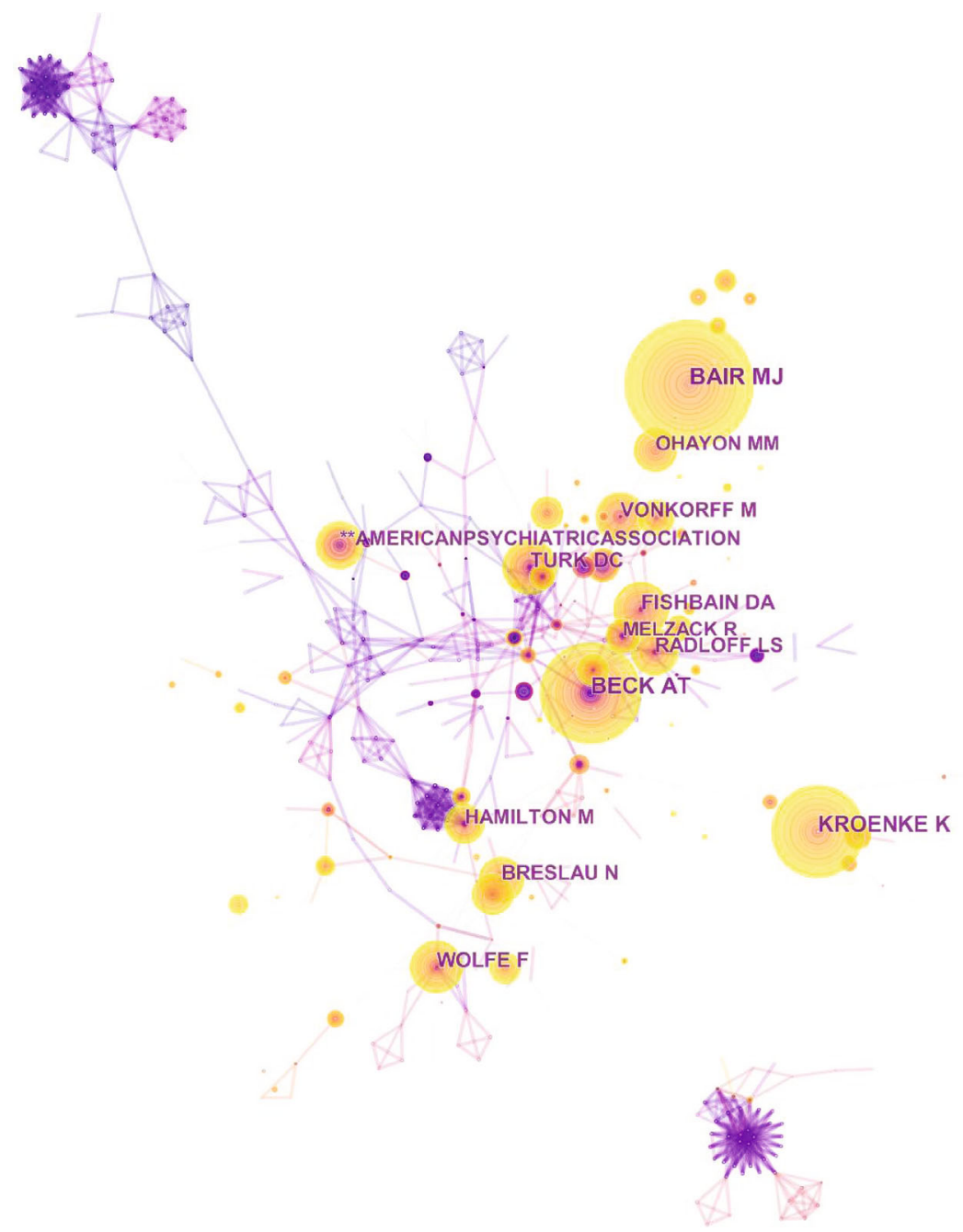

FIgURE 9: The analysis of authors. Network map of active authors that contributed to pain and depression research.

TABle 2: The top 10 authors, cocited authors, and cocited references in the pain and depression research.

\begin{tabular}{lcccc}
\hline Author & $\begin{array}{c}\text { Published } \\
\text { articles }\end{array}$ & Cocited author & $\begin{array}{c}\text { Cited } \\
\text { times }\end{array}$ & Cocited reference \\
\hline Kroenke K & 35 & Bair MJ & 447 & Bair MJ, 2003, Arch Intern Med, V163, P2433 \\
Bair MJ & 21 & Beck AT & 403 & Bair MJ, 2004, Psychosom Med, V66, P17 \\
Negus SS & 19 & Kroenke K & 337 & Ohayon MM, 2003, Arch Gen Psychiat, V60, P39 \\
Wang SJ & 19 & Turk DC & 236 & Kroenke K, 2011, J Pain, V12, P964 \\
Wu JW & 18 & Fishbain DA & 228 & Blumer D, 1982, J Nerv Ment Dis, V170, P381 \\
Ferrari MD & 15 & Wolfe F & 223 & Romano JM, 1985, Psychol Bull, V97, P18 \\
Hung CI & 15 & Vonkorff M & 202 & Arnow BA, 2006, Psychosom Med, V68, P262 \\
Liu CY & 15 & ** American Psychiatric & 199 & Karp JF, 2005, J Clin Psychiat, V66, P591 \\
Arnold LM & 13 & Association & & 46 \\
Ayata C & 13 & Radloff LS & 195 & Currie SR, 2004, Pain, V107, P54 \\
\hline
\end{tabular}

cocitation map of references, the "rehabilitation outcome" was labeled as the largest cluster \#0, followed by "home care" as the second largest cluster \#1, "pain comorbidity" as the third largest cluster \#2, and "depressive disease." According to the keywords with strongest citation bursts, the results found that the top 47 keywords that began in 1991 were as follows: "disease," "illness," "chronic pain," and "inventory." And the top 47 keywords by the end of 2018 were as follows: 


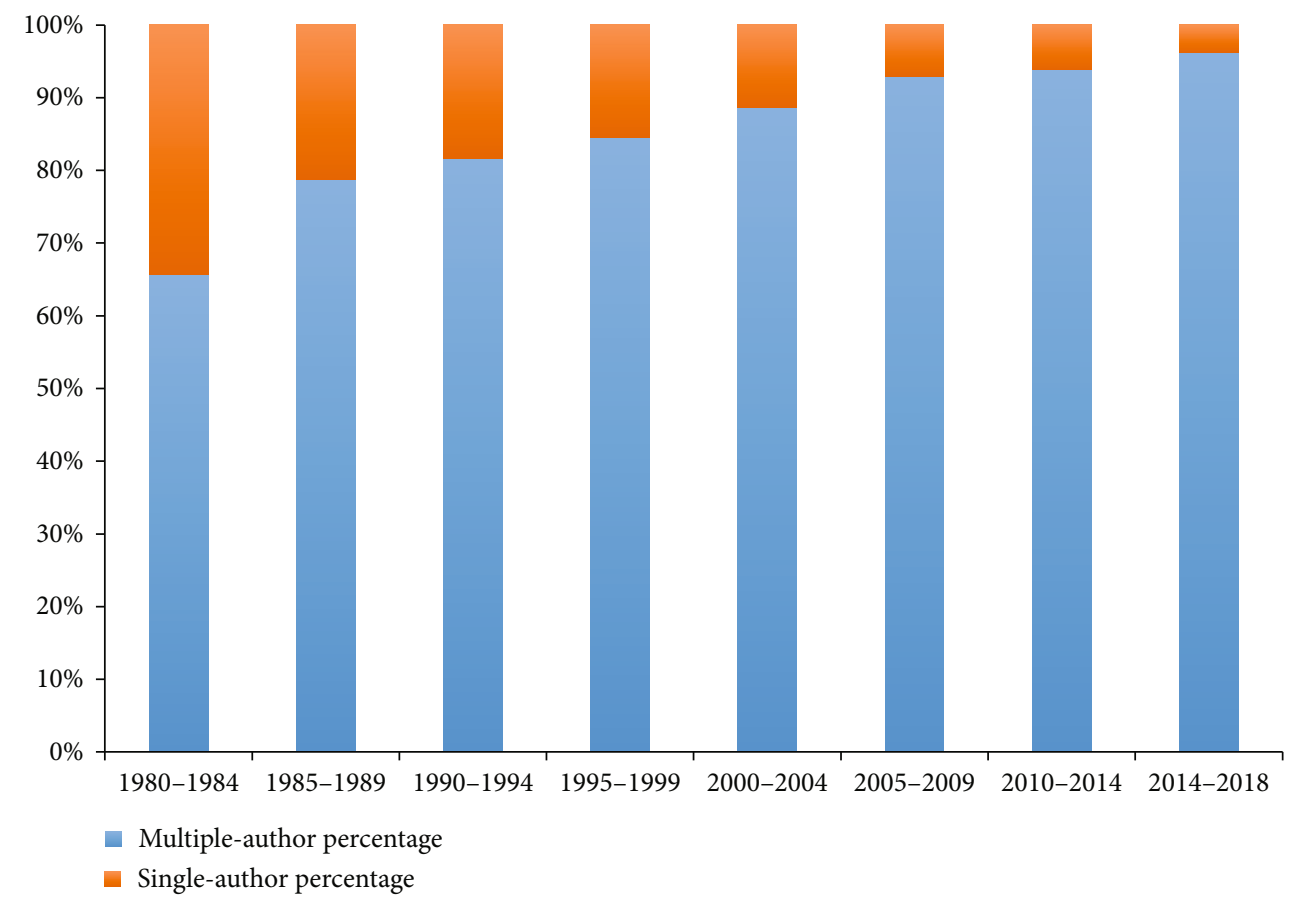

FIGURE 10: Trends in the percentage of single- vs multiple-authored articles per 5 years.

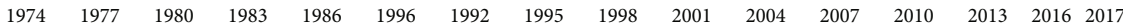

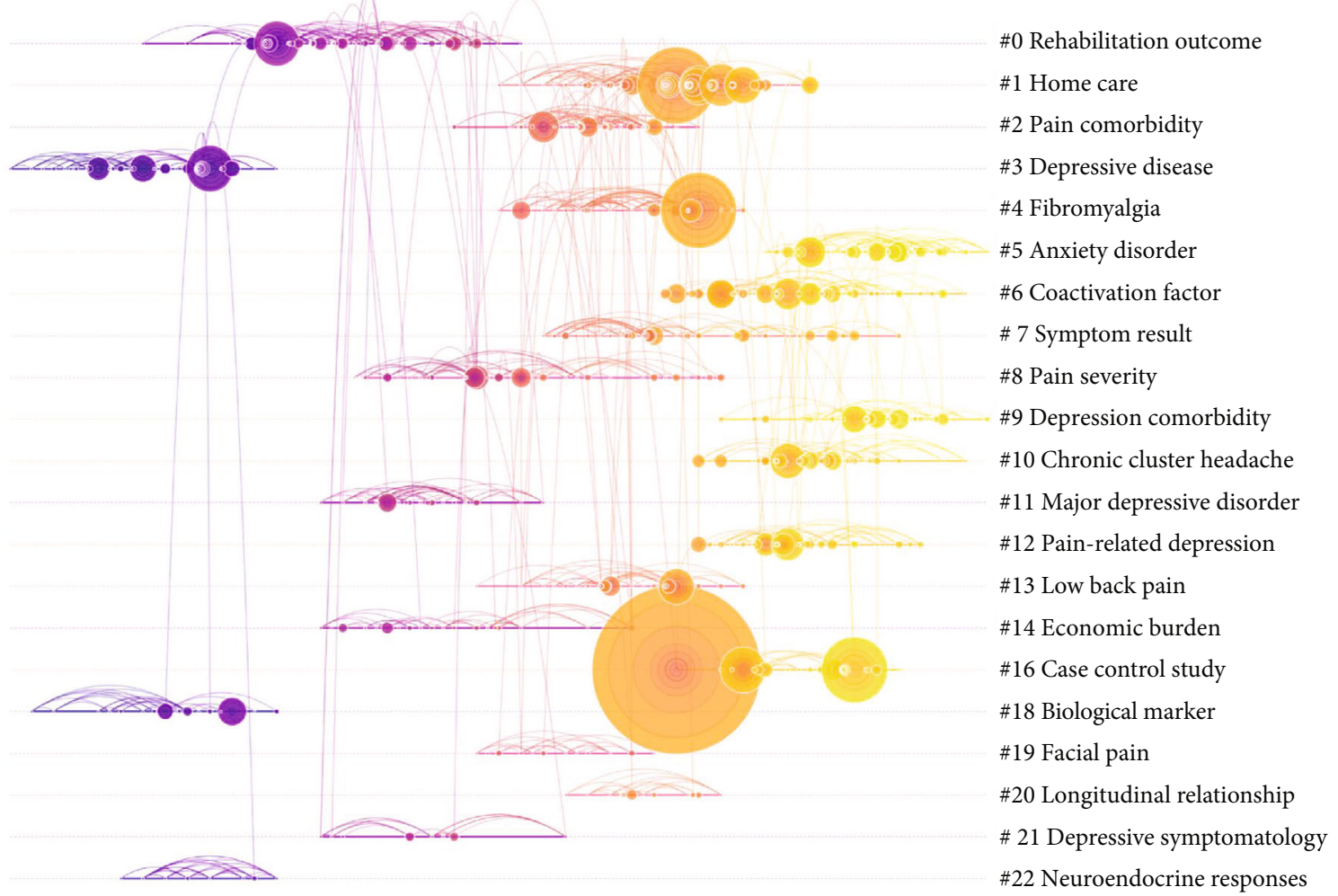

FIgURE 11: The analysis of references. Cocitation map (timeline view) of references from publications on to pain and depression research.

"older adult" (2014-2018), "validity" (2015-2018), “impact" (2016-2018), and "association" (2016-2018). In the last 10 years, because of the aging of the global population, the comorbidity of pain and depression research was rapidly increasing in the older adult. The comorbid pain and depression research gradually transitioned from phenomenon to mechanism. The study by Descalzi et al. [41] showed that their findings not only confirm molecular links on comorbid pain 
Top 47 keywords with the strongest citation bursts

\begin{tabular}{|c|c|c|c|c|c|}
\hline Keyword & Year & Strength & Begin & End & 1980-2018 \\
\hline Disease & 1980 & 12.3787 & 1991 & 2002 & \\
\hline Illness & 1980 & 8.3916 & 1991 & 2002 & \\
\hline Chronic pain & 1980 & 4.967 & 1991 & 1994 & \\
\hline Inventory & 1980 & 5.4845 & 1991 & 2003 & \\
\hline Morphine & 1980 & 8.5078 & 1992 & 2002 & \\
\hline Amitriptyline & 1980 & 4.0448 & 1992 & 2004 & \\
\hline Migraine & 1980 & 4.648 & 1992 & 1995 & \\
\hline Spinal cord & 1980 & 4.6935 & 1992 & 2001 & \\
\hline Headache & 1980 & 5.8799 & 1992 & 2003 & \\
\hline Mood & 1980 & 4.8201 & 1994 & 2001 & \\
\hline Young adult & 1980 & 12.5307 & 1995 & 2007 & \\
\hline Chronic musculoskeletal pain & 1980 & 5.1473 & 1999 & 2004 & \\
\hline Perception & 1980 & 7.7464 & 1999 & 2010 & \\
\hline Pain threshold & 1980 & 4.5929 & 1999 & 2004 & \\
\hline Adjustment & 1980 & 5.7533 & 2000 & 2006 & \\
\hline Psychopathology & 1980 & 3.7059 & 2000 & 2003 & \\
\hline Predictor & 1980 & 4.0156 & 2001 & 2009 & \\
\hline Chronic fatigue syndrome & 1980 & 5.5171 & 2002 & 2006 & \\
\hline Back pain & 1980 & 7.8648 & 2002 & 2012 & \\
\hline Children & 1980 & 5.5171 & 2002 & 2006 & \\
\hline Psychiatric comorbidity & 1980 & 6.7621 & 2003 & 2008 & \\
\hline Somatization & 1980 & 5.6999 & 2003 & 2004 & \\
\hline Community & 1980 & 4.2329 & 2003 & 2005 & \\
\hline Somatic symptom & 1980 & 6.8384 & 2004 & 2011 & \\
\hline Double blind & 1980 & 13.8014 & 2004 & 2012 & \\
\hline Hospital anxiety & 1980 & 4.0879 & 2005 & 2006 & \\
\hline Risk factor & 1980 & 4.1465 & 2006 & 2009 & \\
\hline Arthritis & 1980 & 5.2344 & 2006 & 2008 & \\
\hline Rheumatoid arthritis & 1980 & 3.9581 & 2007 & 2008 & \\
\hline Care & 1980 & 6.4107 & 2008 & 2009 & \\
\hline General population & 1980 & 4.7285 & 2008 & 2012 & \\
\hline Duloxetine & 1980 & 7.0721 & 2009 & 2011 & \\
\hline Psychiatric disorder & 1980 & 4.1321 & 2009 & 2011 & \\
\hline Epidemiology & 1980 & 4.7424 & 2009 & 2010 & \\
\hline Validation & 1980 & 5.8159 & 2010 & 2012 & \\
\hline Antidepressant & 1980 & 5.0428 & 2010 & 2012 & \\
\hline Musculoskeletal pain & 1980 & 11.2256 & 2012 & 2016 & \\
\hline Randomized controlled trial & 1980 & 8.4133 & 2012 & 2014 & \\
\hline Stress & 1980 & 6.4966 & 2013 & 2015 & \\
\hline Severity & 1980 & 13.474 & 2013 & 2016 & \\
\hline Mechanism & 1980 & 8.0174 & 2013 & 2015 & \\
\hline Meta-analysis & 1980 & 12.1645 & 2013 & 2016 & \\
\hline Neuropathic pain & 1980 & 14.4343 & 2014 & 2016 & \\
\hline Older adult & 1980 & 10.138 & 2014 & 2018 & \\
\hline Validity & 1980 & 8.9154 & 2015 & 2018 & \\
\hline Impact & 1980 & 5.9866 & 2016 & 2018 & \\
\hline Association & 1980 & 7.1549 & 2016 & 2018 & \\
\hline
\end{tabular}

FIGURE 12: The keywords with the strongest citation bursts of publications on pain and depression research. 


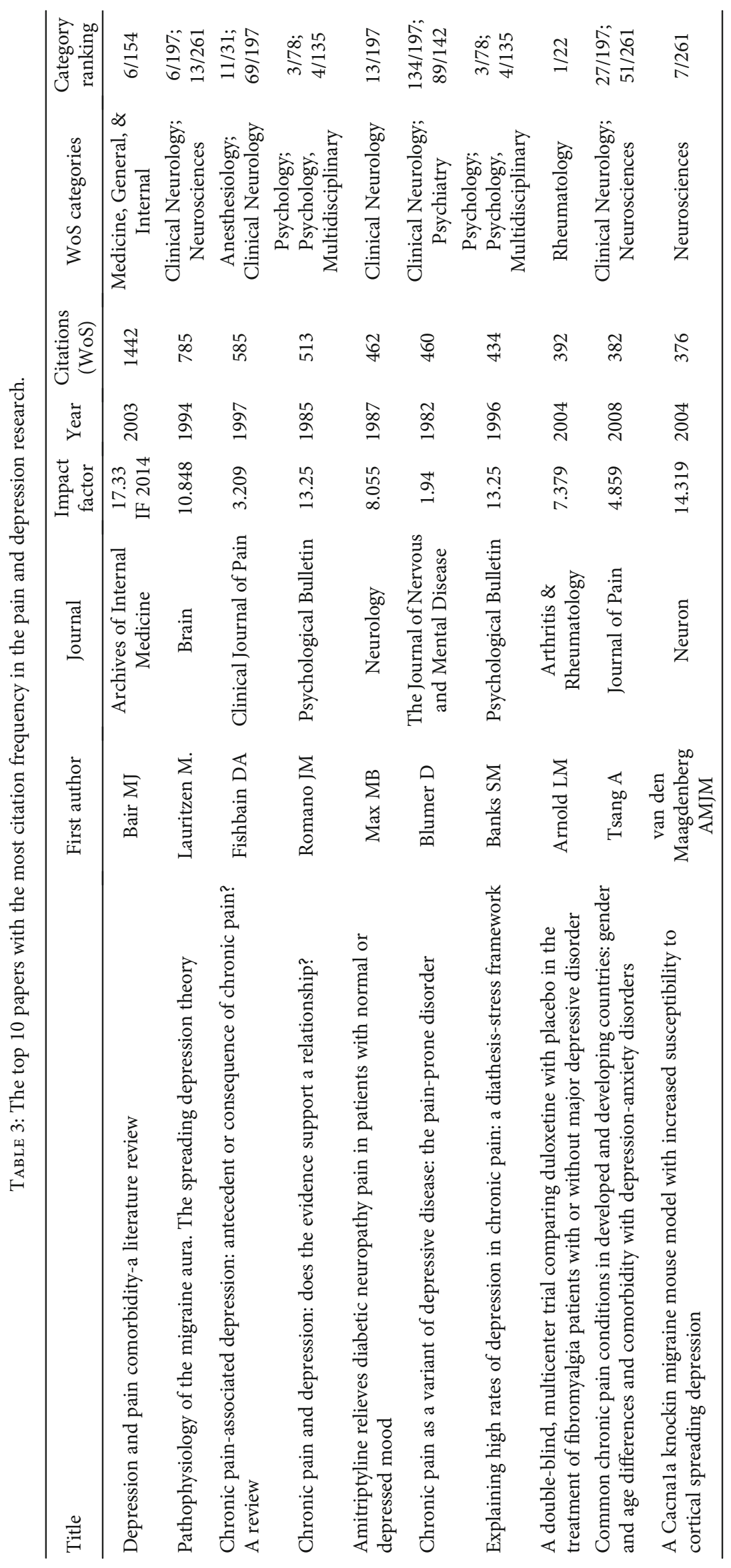


and depression but also provided a potential therapeutic approach.

4.3. Strengths and Limitations. This study is the first bibliometric analysis to assess the trends of the comorbid pain and depression research from SCI-Expanded of Web of Science in the recent forty years. Furthermore, to gain rich data, it was not restricted to one academic journal. The 2,519 papers on comorbid pain and depression research were published in 251 different academic journals. Moreover, bibliometric analysis of our study not only covered the number of publications, citations, journals, and collaborations between countries/institutions/authors but also included analysis of keywords, cocitation analysis on references and authors, Web of Science subject categories, and types of pain.

This bibliometric study has some limitations. The electronic database is limited to SCI-Expanded of Web of Science, and other electronic databases are not searched and analyzed, for example, PubMed, Embase, Scopus, Cochrane Library. Furthermore, the non-English papers were excluded. Most included papers use English in this study; however, the limitation may induce a publication bias. The last limitation is that influential publications were not cited with high citation frequency, since some potential influential papers were published recently, which could be not cited with frequent times.

\section{Conclusions}

This study provides historical insights into the trends of comorbidity of pain and depression research. The number of published papers significantly increased over the last 40 years, and the overall trend of publications increased from 5 publications in 1980 to 179 publications in 2018. Although this study presents several limitations, it adequately exposes the trends of comorbidity of pain and depression research. Based on the type of pain, the research topics of the 2,519 papers included in this work mainly focused on headache, low back pain, and fibromyalgia. The results of our study could provide useful information for pain and depression researchers, funding agencies, and policy makers.

\section{Data Availability}

All research data used to support the findings of this study are included within the article and the supplementary information file.

\section{Conflicts of Interest}

The authors report no conflicts of interest.

\section{Authors' Contributions}

Xue-Qiang Wang and Meng-Si Peng contributed equally to this work.

\section{Acknowledgments}

This work was supported by the National Natural Science Foundation of China (81871844); Fok Ying-Tong Education Foundation of China (161092); Scientific and Technological Research Program of the Shanghai Science and Technology Committee (9080503100); Shanghai Key Lab of Human Performance (Shanghai University of Sport) (11DZ2261100); Shuguang Program supported by Shanghai Education Development Foundation; and Shanghai Municipal Education Commission (18SG48).

\section{Supplementary Materials}

Supplementary 1. Supplementary Figure 1: Overview of the paper selection process.

Supplementary 2. Supplementary Figure 2: The number of papers, citations, citations per paper, open access papers, and $\mathrm{H}$-index of the top 10 institutions.

Supplementary 3. Supplementary Table 1: Raw data on journal sources of pain and depression publications.

Supplementary 4. Supplementary Table 2: Raw data on countries/territories involved in pain and depression publications.

Supplementary 5. Supplementary Table 3: Raw data on institutions involved in pain and depression publications.

\section{References}

[1] U. E. Makris, R. C. Abrams, B. Gurland, and M. C. Reid, "Management of persistent pain in the older patient: a clinical review," Journal of the American Medical Association, vol. 312, no. 8, pp. 825-836, 2014.

[2] A. Qaseem, T. J. Wilt, R. M. McLean, M. A. Forciea, and for the Clinical Guidelines Committee of the American College of Physicians, "Noninvasive treatments for acute, subacute, and chronic low back pain: a clinical practice guideline from the American College of Physicians," Annals of Internal Medicine, vol. 166, no. 7, pp. 514-530, 2017.

[3] A. M. Taylor, K. Phillips, K. V. Patel et al., "Assessment of physical function and participation in chronic pain clinical trials: IMMPACT/OMERACT recommendations," Pain, vol. 157, no. 9, pp. 1836-1850, 2016.

[4] A. K. Walker, A. Kavelaars, C. J. Heijnen, and R. Dantzer, "Neuroinflammation and comorbidity of pain and depression," Pharmacological Reviews, vol. 66, no. 1, pp. 80-101, 2014.

[5] J. Dahlhamer, J. Lucas, C. Zelaya et al., "Prevalence of chronic pain and high-impact chronic pain among adults - United States, 2016," MMWR: Morbidity and Mortality Weekly Report, vol. 67, no. 36, pp. 1001-1006, 2018.

[6] J. A. Davis, R. L. Robinson, T. K. Le, and J. Xie, "Incidence and impact of pain conditions and comorbid illnesses," Journal of Pain Research, vol. 4, pp. 331-345, 2011.

[7] B. Gavilán-Carrera, V. Segura-Jiménez, F. Estévez-López et al., "Association of objectively measured physical activity and sedentary time with health-related quality of life in women with fibromyalgia: The al-Ándalus project," Journal of Sport and Health Science, vol. 8, no. 3, pp. 258-266, 2019. 
[8] X. Q. Wang, W. Gu, B. L. Chen et al., "Effects of whole-body vibration exercise for non-specific chronic low back pain: an assessor-blind, randomized controlled trial," Clinical Rehabilitation, vol. 33, no. 9, pp. 1445-1457, 2019.

[9] N. Henschke, S. J. Kamper, and C. G. Maher, "The epidemiology and economic consequences of pain," Mayo Clinic Proceedings, vol. 90, no. 1, pp. 139-147, 2015.

[10] G. L. Farren, T. Zhang, X. Gu, and K. T. Thomas, "Sedentary behavior and physical activity predicting depressive symptoms in adolescents beyond attributes of health-related physical fitness," Journal of Sport and Health Science, vol. 7, no. 4, pp. 489-496, 2018.

[11] D. R. Singla, B. A. Kohrt, L. K. Murray, A. Anand, B. F. Chorpita, and V. Patel, "Psychological treatments for the world: lessons from low- and middle-income countries," Annual Review of Clinical Psychology, vol. 13, no. 1, pp. 149-181, 2017.

[12] L. S. Rotenstein, M. A. Ramos, M. Torre et al., "Prevalence of depression, depressive symptoms, and suicidal ideation among medical students: a systematic review and meta-analysis," Journal of the American Medical Association, vol. 316, no. 21, pp. 2214-2236, 2016.

[13] G. Y. Lim, W. W. Tam, Y. Lu, C. S. Ho, M. W. Zhang, and R. C. Ho, "Prevalence of depression in the community from 30 countries between 1994 and 2014," Scientific Reports, vol. 8, no. 1, 2018.

[14] M. Sado, K. Yamauchi, N. Kawakami et al., "Cost of depression among adults in Japan in 2005," Psychiatry and Clinical Neurosciences, vol. 65, no. 5, pp. 442-450, 2011.

[15] J. X. Li, "Pain and depression comorbidity: a preclinical perspective," Behavioural Brain Research, vol. 276, pp. 92-98, 2015.

[16] D. Barman, S. Mishra, J. Mishra, P. Mahapatra, and M. Manjareeka, "Association between depression and acute pain in adults attending a tertiary care hospital in Bhubaneswar," Journal of Clinical and Diagnostic Research, vol. 9, pp. CC08-CC11, 2015.

[17] K. J. Bar, G. Wagner, M. Koschke et al., "Increased prefrontal activation during pain perception in major depression," Biological Psychiatry, vol. 62, no. 11, pp. 1281-1287, 2007.

[18] T. Giesecke, R. H. Gracely, D. A. Williams, M. E. Geisser, F. W. Petzke, and D. J. Clauw, "The relationship between depression, clinical pain, and experimental pain in a chronic pain cohort," Arthritis and Rheumatism, vol. 52, no. 5, pp. 1577-1584, 2005.

[19] I. Wormell, "Bibliometric navigation tools for users of subject portals," Journal of Information Science, vol. 29, no. 3, pp. 193203, 2003.

[20] S. H. Zyoud and D. Fuchs-Hanusch, "A bibliometric-based survey on AHP and TOPSIS techniques," Expert Systems with Applications, vol. 78, pp. 158-181, 2017.

[21] Y. Miao, S. Y. Xu, L. S. Chen, G. Y. Liang, Y. P. Pu, and L. H. Yin, "Trends of long noncoding RNA research from 2007 to 2016: a bibliometric analysis," Oncotarget, vol. 8, no. 47, pp. 83114-83127, 2017.

[22] L. Caes, K. E. Boerner, C. T. Chambers et al., “A comprehensive categorical and bibliometric analysis of published research articles on pediatric pain from 1975 to 2010," Pain, vol. 157, no. 2, pp. 302-313, 2016.

[23] N. L. Stout, C. M. Alfano, C. W. Belter et al., “A bibliometric analysis of the landscape of cancer rehabilitation research
(1992-2016)," JNCI: Journal of the National Cancer Institute, vol. 110, no. 8, pp. 815-824, 2018.

[24] C. S. Wiysonge, O. A. Uthman, P. M. Ndumbe, and G. D. Hussey, "A bibliometric analysis of childhood immunization research productivity in Africa since the onset of the expanded program on immunization in 1974," BMC Medicine, vol. 11, no. 1, 2013.

[25] C. Boudry, C. Baudouin, and F. Mouriaux, "International publication trends in dry eye disease research: a bibliometric analysis," The Ocular Surface, vol. 16, no. 1, pp. 173-179, 2018.

[26] C. Robert, C. S. Wilson, A. Venuta, M. Ferrari, and C. D. Arreto, "Evolution of the scientific literature on drug delivery: a 1974-2015 bibliometric study," Journal of Controlled Release, vol. 260, pp. 226-233, 2017.

[27] C. Chen, "Searching for intellectual turning points: progressive knowledge domain visualization," Proceedings of the National Academy of Sciences of the United States of America, vol. 101, Supplement 1, pp. 5303-5310, 2004.

[28] J. E. Hirsch, “An index to quantify an individual's scientific research output," Proceedings of the National Academy of Sciences of the United States of America, vol. 102, no. 46, pp. 16569-16572, 2005.

[29] L. Leydesdorff, S. Carley, and I. Rafols, "Global maps of science based on the new Web-of-Science categories," Scientometrics, vol. 94, no. 2, pp. 589-593, 2013.

[30] G. Gesztelyi and D. Bereczki, "Disability is the major determinant of the severity of depressive symptoms in primary headaches but not in low back pain," Cephalalgia, vol. 25 , no. 8 , pp. 598-604, 2005.

[31] M. J. Bair, R. L. Robinson, W. Katon, and K. Kroenke, "Depression and pain comorbidity - a literature review," Archives of Internal Medicine, vol. 163, no. 20, pp. 2433-2445, 2003.

[32] S. M. Banks and R. D. Kerns, "Explaining high rates of depression in chronic pain: a diathesis-stress framework," Psychological Bulletin, vol. 119, no. 1, pp. 95-110, 1996.

[33] M. Lauritzen, "Pathophysiology of the migraine aura: the spreading depression theory," Brain, vol. 117, no. 1, pp. 199210, 1994.

[34] J. M. Romano and J. A. Turner, "Chronic pain and depression - does the evidence support a relationship," Psychological Bulletin, vol. 97, no. 1, pp. 18-34, 1985.

[35] A. M. J. M. van den Maagdenberg, D. Pietrobon, T. Pizzorusso et al., "A Cacnala knockin migraine mouse model with increased susceptibility to cortical spreading depression," Neuron, vol. 41, no. 5, pp. 701-710, 2004.

[36] L. M. Arnold, Y. Lu, L. J. Crofford et al., "A double-blind, multicenter trial comparing duloxetine with placebo in the treatment of fibromyalgia patients with or without major depressive disorder," Arthritis and Rheumatism, vol. 50, no. 9, pp. 2974-2984, 2004.

[37] M. B. Max, M. Culnane, S. C. Schafer et al., "Amitriptyline relieves diabetic neuropathy pain in patients with normal or depressed mood," Neurology, vol. 37, no. 4, pp. 589-596, 1987.

[38] D. A. Fishbain, R. Cutler, H. L. Rosomoff, and R. S. Rosomoff, "Chronic pain-associated depression: antecedent or consequence of chronic pain? A review," The Clinical Journal of Pain, vol. 13, no. 2, pp. 116-137, 1997.

[39] A. Tsang, M. von Korff, S. Lee et al., "Common chronic pain conditions in developed and developing countries: gender and age differences and comorbidity with depression-anxiety 
disorders," The Journal of Pain, vol. 9, no. 10, pp. 883-891, 2008.

[40] D. Blumer and M. Heilbronn, "Chronic pain as a variant of depressive disease - the pain-prone disorder," The Journal of Nervous and Mental Disease, vol. 170, no. 7, pp. 381-406, 1982.

[41] G. Descalzi, V. Mitsi, I. Purushothaman et al., "Neuropathic pain promotes adaptive changes in gene expression in brain networks involved in stress and depression," Science Signaling, vol. 10, no. 471, article eaaj1549, 2017. 


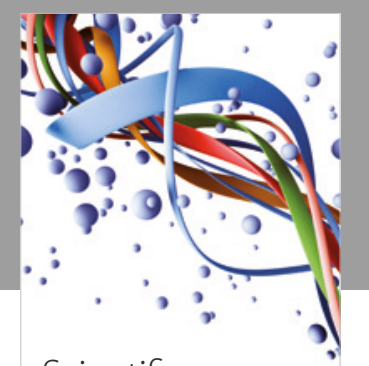

Scientifica
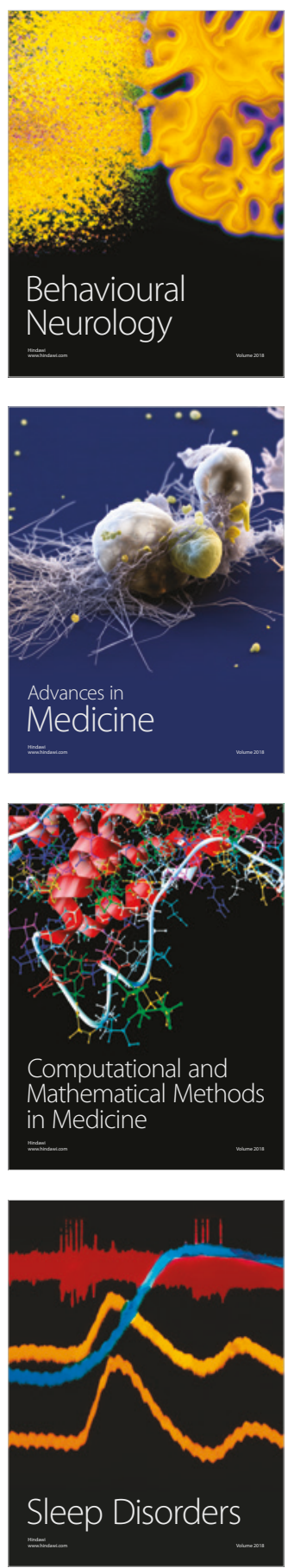

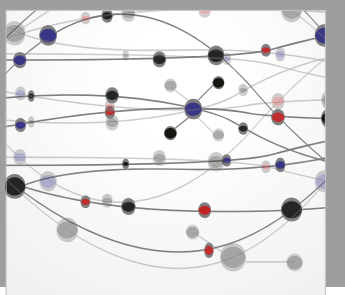

The Scientific World Journal

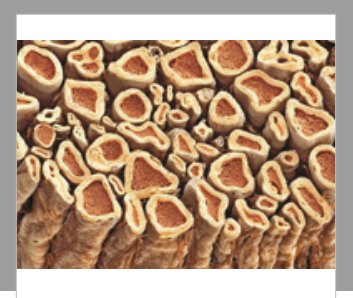

Case Reports in

Neurological Medicine

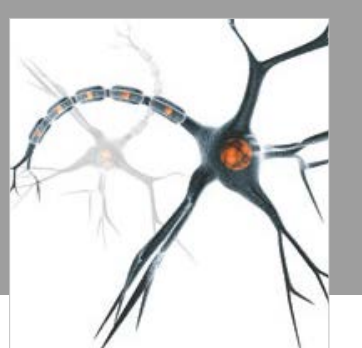

Neural Plasticity

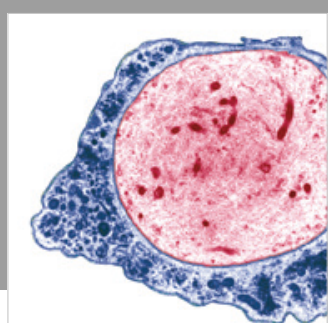

Multiple Sclerosis

International

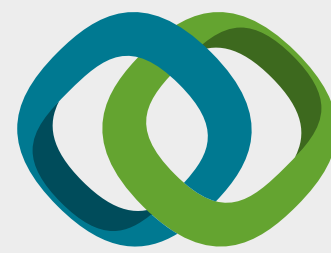

Hindawi

Submit your manuscripts at

www.hindawi.com
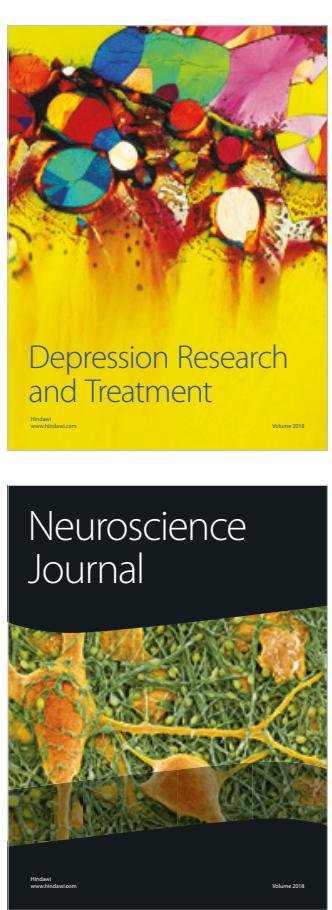

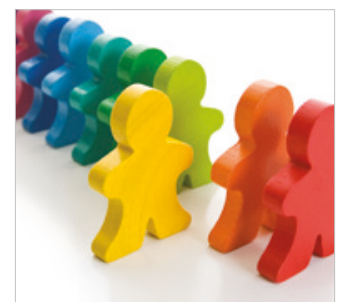

Autism

Research and Treatment
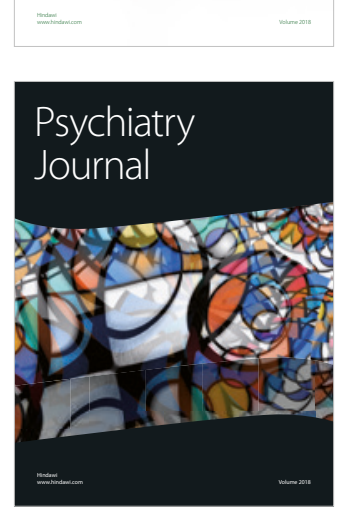
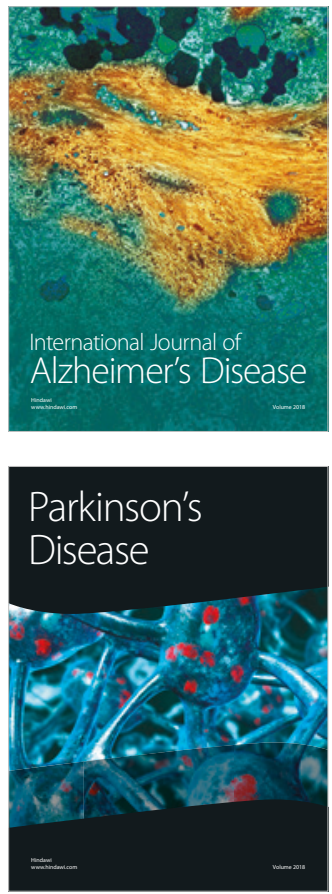
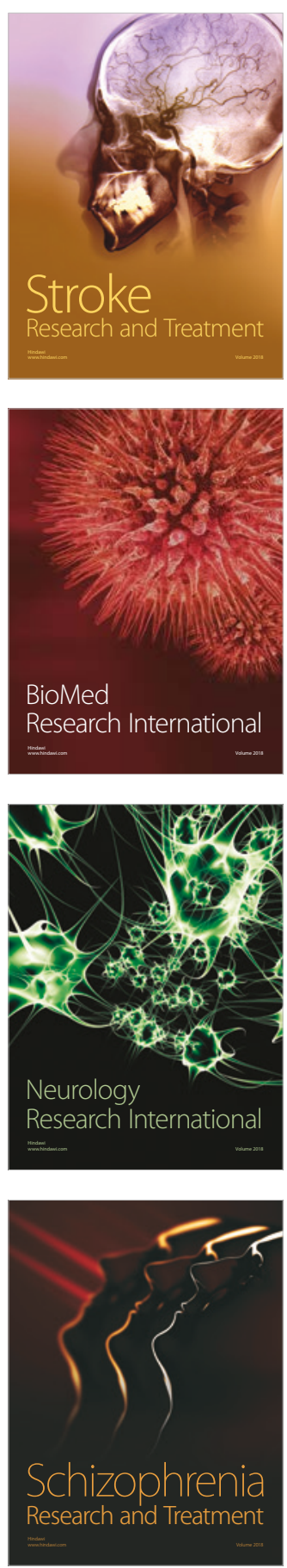